\title{
PENGARUH GETARAN DAN KEBISINGAN TERHADAP KELELAHAN KERJA PADA AWAK KAPAL IKAN TIPE POLE AND LINE
}

\author{
Monalisa Manuputty \\ e-mail: monalisa ftunpatti@yahoo.com \\ Fakultas Teknik Universitas Pattimura Ambon
}

\begin{abstract}
ABSTRAK
Getaran yang dirasakan oleh awak kapal adalah getaran seluruh tubuh yang dihasilkan karena getaran yang terjadi saat mesin beroperasi. Getaran frekuensi rendah dapat mengakibatkan mabuk, ketidakstabilan tubuh dan kelelahan. Kebisingan adalah segala bunyi yang tidak dikehendaki yang dapat memberi pengaruh negatif terhadap kesehatan dan kesejahteraan seseorang maupun populasi. Kebisingan dapat menimbulkan gangguan kesehatan pada pekerja seperti auditorial (daya dengar pekerja menurun) serta dampak non- auditorial berupa kelelahan kerja pada tenaga kerja yang terpapar. Kebisingan di kapal dihasilkan oleh mesin utama dan mesin bantu seperti generator listrik dan mesin tambahan untuk menggerakkan derek. Tujuan penelitian ini adalah untuk mengetahui hubungan antara getaran dan kebisingan dengan kelelahan kerja pada awak kapal ikan tipe pole and line yang berpangkalan di desa Tulehu. Pendekatan yang dipakai dalam penelitian ini adalah desain penelitian cross-sectional. Penelitian ini dilaksanakan pada bulan Juli - Oktober 2018. Faktor pada lingkungan kerja yang diukur adalah tingkat kebisingan dan getaran. Sampel pada penelitian ini adalah awak kapal tipe ikan pole and line yang berjumlah 40 orang. Variabel atau kontruks dalam penelitian ini adalah kebisingan, getaran, kelelahan kerja. Kebisingan diukur dengan sound level meter, getaran dengan vibration meter, dan kelelahan kerja dengan kuesioner KAUPK2 (Kuesioner Alat Ukur Perasaan Kelelahan Kerja). Analisis data menggunakan analisis PLS (Partial Least Square). Berdasarkan hasil uji hipotesis diketahui secara signifikan getaran dan kebisingan berpengaruh terhadap kelelahan kerja sebesar $42,2 \%$ dan 57,8 \% dipengaruhi oleh faktor lain yang tidak diteliti.
\end{abstract}

Kata Kunci: Getaran, Kebisingan, Kelelahan Kerja

\section{PENDAHULUAN}

Kapal perikanan adalah salah satu tempat kerja yang beresiko tinggi terhadap keselamatan dan kesehatan awak kapal. Awak kapal pada kapal perikanan bekerja disemua kondisi laut yang tidak bersahabat, hujan, badai dan suhu yang esktrem, tidak ada jam kerja tetap dan irama kerja ditentukan oleh laut dan tangkapannya. Bahaya penyakit yang dialami oleh awak kapal pada kapal perikanan antara lain berasal dari faktor fisika yaitu getaran, kebisingan dan suhu, faktor kimia, faktor biologi dan faktor psikososial (ILO, 2014).

Ada karakteristik unik tertentu atas kedudukan pelaut yang harus dipertimbangkan ketika mempelajari lingkungan kerja di atas kapal. Pekerjaan pelaut dan awak kapal secara keseluruhan banyak berbeda dari tempat kerja di daratan. Yang patut dipertimbangkan adalah kondisi fisik dari lingkungan kerja di kapal. Selain itu, lingkungan kerja di kapal dipengaruhi juga antara lain oleh kebisingan dan getaran (Kristiansen, dalam Lang, 2011). Getaran yang dirasakan oleh awak kapal adalah getaran seluruh tubuh yang dihasilkan karena getaran yang terjadi saat mesin beroperasi. Getaran frekuensi rendah dapat mengakibatkan mabuk, ketidakstabilan tubuh dan kelelahan (ILO, 2013). Di Indonesia, nilai ambang batas paparan getaran untuk kesehatan dan kenyamanan diatur oleh Keputusan
Menteri Tenaga Kerja Nomor. PER.13/MEN/X/2011 tentang Nilai Ambang Batas Faktor Fisika dan Kimia di Tempat Kerja. NAB getaran yang kontak langsung maupun tidak langsung pada seluruh tubuh ditetapkan sebesar 0,5 meter per detik kuadrat $\left(\mathrm{m} / \mathrm{det}^{2}\right)$.

Kebisingan adalah segala bunyi yang tidak dikehendaki yang dapat memberi pengaruh negatif terhadap kesehatan dan kesejahteraan seseorang maupun populasi. Lingkungan kerja yang mempunyai kebisingan melebihi Nilai Ambang Batas (NAB) dapat menimbulkan gangguan kesehatan pekerja seperti auditorial (daya dengar pekerja menurun) serta dampak non-auditorial berupa kelelahan pekerja. Kebisingan di kapal dihasilkan oleh mesin utama dan mesin bantu seperti generator listrik dan mesin tambahan untuk menggerakkan derek (Carter \& Schreiner, 2014). Hampir semua negara merekomendasikan bahwa paparan kebisingan bagi semua pekerja harus dikendalikan di bawah tingkat $85 \mathrm{~dB}(\mathrm{~A})$ selama delapan jam dalam satu hari kerja untuk meminimalkan kerusakan atau gangguan pendengaran. Di Indonesia, nilai ambang batas paparan kebisingan adalah $85 \mathrm{~dB}(\mathrm{~A})$ diatur oleh Keputusan Menteri Tenaga Kerja Nomor. PER.13/MEN/X/2011 tentang Nilai Ambang Batas Faktor Fisika dan Kimia di Tempat Kerja.

Pengertian kelelahan secara sempit memang hanya sebatas pada lelah fisik yang dirasakan saja. 
Hal ini dikarenakan setiap orang yang merasakan kelelahan hanya terbatas pada keluhan-keluhan fisik yang mereka rasakan saja. Gejala yang ditimbulkan, perubahan fisik dan perasaan yang dirasakan memang berbeda pada masing-masing individu. Dari sudut pandang keselamatan kerja, medis dan psikologi pun memiliki definisi-definisi atau pengertian yang berbeda-beda mengenai kelelahan, tergantung dari disiplin ilmu yang dipelajari. (Suma'mur, 2009).

Kelelahan kerja merupakan kriteria yang kompleks yang tidak hanya menyangkut kelelahan fisiologis dan psikologis tetapi dominan hubungannya dengan penurunan kinerja fisik, adanya perasaan lelah, penurunan motivasi dan penurunan produktivitas kerja (Lubis, 2009).

Menurut Koemer (1997) kelelahan kerja merupakan gejala yang ditandai adanya perasaan lelah dan kita akan merasakan malas dan aktifitas akan melemah serta ketidakseimbangan pada kondisi tubuh. Kelelahan mempengaruhi aktivitas fisik, mental, dan tingkat emosional seseorang, dimana dapat mengakibatkan kurangnya kewaspadaan, yang ditandai dengan kemunduran reaksi pada sesuatu dan berkurangnya kemampuan motorik (Ariani, 2009).

Menurut Siswanto (Lubis, 2009), faktor penyebab kelelahan kerja berkaitan dengan: a) Pengorganisasian kerja yang tidak menjamin istirahat dan rekreasi, variasi kerja dan intensitas pembebanan fisik yang tidak serasi dengan pekerjaan; b) Faktor Psikologis, misalnya rasa tanggung jawab dan kuatir yang berlebihan, serta konflik yang kronis/ menahun; c) Lingkungan kerja yang tidak menjamin kenyamanan kerja dan menimbulkan pengaruh negatif terhadap kesehatan pekerja; d) Status kesehatan (penyakit) dan status gizi; e) Pekerjaan yang monoton atau lingkungan kerja yang membosankan.

Setyawati (1994) menyatakan bahwa kelelahan yang disebabkan oleh faktor lingkungan fisik di tempat kerja antara lain oleh getaran dan kebisingan.

\section{TUJUAN}

Tujuan dari penelitian ini adalah untuk melihat pengaruh getaran dan kebisingan pada kapal ikan tipe pole and line terhadap kelelahan kerja yang dialami oleh awak kapal.

\section{METODE}

Pendekatan yang dipakai dalam penelitian ini adalah desain penelitian. Penelitian dilakukan pada 4 buah kapal ikan tipe pole and line yang berada di desa Tulehu, Ambon. Populasi dalam penelitian ini adalah seluruh awak kapal dari kapal-kapal tersebut. Jumlah responden ditentukan berdasarkan aturan dari analisis data yang digunakan dalam penelitian ini yaitu Partial Least Square (PLS) dihitung berdasarkan hasil kali jumlah indikator dengan faktor perkalian yang dipilih antara 5 sampai 10 dan jumlah sampel yang dipilih harus lebih besar dari 30 orang.

Indikator dalam penelitian ini berjumlah 3 yaitu variabel laten eksogen dengan indikator getaran dan kebisingan. Variabel laten endogen kelelahan kerja. Berdasarkan 3 indikator dan faktor perkalian 10 maka didapatkan jumlah responden 30 orang. Karena jumlah sampel/respoden harus lebih besar dari 30 maka ditentukan jumlah awak kapal yang menjadi responden adalah 40 orang. Dari tiap kapal diambil 10 orang awak kapal untuk dijadikan responden. Getaran kapal diukur dengan vibration meter, kebisingan diukur dengan sound level meter, dan kelelahan kerja diukur dengan Kuesioner Alat Ukur Perasaan Kelelahan Kerja (KAUPK2)

Hipotesis dalam penelitian ini adalah:

1. H1 : Ada pengaruh faktor getaran terhadap kelelahan kerja.

2. H2 : Ada pengaruh faktor kebisingan terhadap kelelahan kerja

Berdasarkan variabel dan indikator yang telah ditentukan maka skema analisis data dibuat seperti pada gambar 1 .

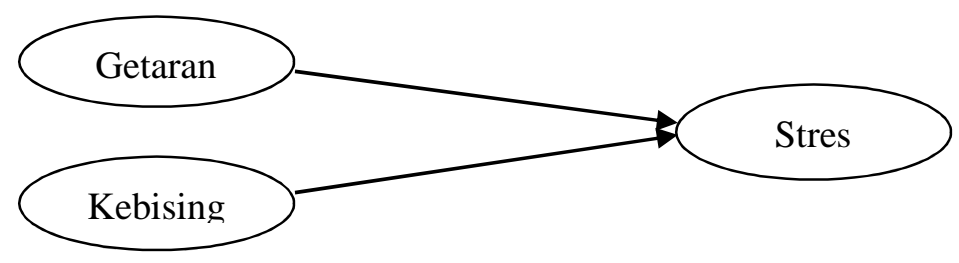

Gambar 1. Skema Analisis Data

\section{HASIL PENELITIAN}

\section{A. Hasil Pengukuran}

Hasil rerata pengukuran tingkat getaran pada kamar mesin 3,5 m/det ${ }^{2}$ sedangkan pada geladak kerja
$0,8 \mathrm{~m} / \mathrm{det}^{2}$, sedangkan pada kamar awak kapal 1,2 $\mathrm{m} / \mathrm{det}^{2}$. Rerata kebisingan pada kamar mesin 90,5 dB dan pada geladak kerja $57 \mathrm{~dB}$ dan kamar awak kapal $86 \mathrm{~dB}$. Data dari kuesioner yang dibagikan dan diisi oleh responden dianalisis dengan 
menggunakan analisis PLS (Partial Least Square).

\section{B. Hasil Analisis}

1. Evaluasi Model Pengukuran (Outer Model). a. Uji Validitas.

Suatu indikator dinyatakan valid jika mempunyai loading faktor diatas 0,7 terhadap kontruks yang dituju. Nilai loading faktor pada masing-masing indikator berada pada nilai yang memenuhi syarat dari valid tidaknya suatu indikator yaitu di atas 0,7 dengan kisaran nilai 0,789-0,826.
Hai ini berarti bahwa indikator yang digunakan dalam penelitian ini adalah valid.

\section{b. Uji Reliabilitas.}

Uji reliabilitas dilakukan dengan melihat nilai composite reliability dari blok indikator yang mengukur kontruks. Jika nilai yang diperoleh di atas 0,7 maka kontruk tersebut dianggap reliabel. Uji reliabel juga dapat dilihat dari nilai Cronbach's Alpha, bila nilai yang didapatkan di atas 0,6 maka konstruk tersebut reliabel.

Berdasarkan nilai yang terlihat pada tabel 1 , kontruks pada penelitian ini dinyatakan reliabel.

Tabel. 1. Nilai Reliabilitas

\begin{tabular}{|l|c|c|}
\hline \multicolumn{1}{|c|}{ Kontruks } & Composite Reliability & Cronbach's Alpha \\
\hline Getaran & 0,714 & 0,701 \\
\hline Kebisingan & 0,705 & 0,665 \\
\hline Kelelahan Kerja & 0,884 & 0,869 \\
\hline
\end{tabular}

\section{Evaluasi Model Struktural (Inner Model).}

Uji pada model struktural dilakukan untuk menguji hubungan antara konstruk laten. Salah satu cara untuk menguji model struktural dengan menggunakan nilai $R$ Square. Nilai $R$ Square adalah koefisien determinasi pada konstruk endogen. Menurut Chin, nilai $\mathrm{R}$ square $>0.67$ adalah kuat, antara 0,33-0,66 termasuk moderat dan $<0.19-$ 0,32 adalah lemah. (Effendi, 2015). Koefisien determinasi pada kontruks endogen dalam penelitian ini bernilai moderat atau sedang karena nilai $\mathrm{R}$ square kelelahan kerja adalah 0,422.

Untuk menilai signifikasi model prediksi dalam pengujian model struktural, dapat dilihat dari nilai t- statistik antara kontruks laten yang ditunjukkan dalam Path Coefficient pada hasil analisis PLS (Tabel 2).

Besarnya nilai original sampel kontruks getaran terhadap kelelahan kerja adalah bernilai positif 0,593 yang berarti terdapat pengaruh positif antara getaran dengan kelelahan kerja. Dapat diinterpretasikan bahwa tingkat getaran yang masih memenuhi syarat atau berada di bawah nilai ambang batas maka kelelahan kerja pada awak kapal semakin berkurang atau sebaliknya bila tingkat getaran dan di atas nilai ambang batas maka tingkat kelelahan kerja pada awak kapal semakin tinggi.

Tabel 2. Path Coefficient antar kontruks

\begin{tabular}{|l|c|c|c|c|}
\hline & Original Sampel & Standar Deviasi & t-statistik & \multirow{2}{*}{ R Square } \\
\hline Getaran $\rightarrow$ Kelelahan Kerja & 0,593 & 0,294 & 2,029 & \multirow{2}{*}{0,422} \\
\hline Kebisingan $\rightarrow$ Kelelahan Kerja & 0,662 & 0,518 & 2,091 & \\
\hline
\end{tabular}

Besarnya nilai original sampel kontruks kebisingan terhadap kelelahan kerja adalah bernilai positif 0,662 yang berarti terdapat pengaruh positif antara kebisingan dengan kelelahan kerja. Dapat diinterpretasikan bahwa tingkat kebisingan yang masih memenuhi syarat atau berada di bawah nilai ambang batas maka kelelahan kerja pada awak kapal semakin berkurang atau sebaliknya bila tingkat kebisingan di atas nilai ambang batas maka tingkat kelelahan kerja pada awak kapal semakin tinggi.

Berdasarkan nilai $\mathrm{R}$ square dapat dikatakan getaran dan kebisingan berpengaruh sebesar 42,2\% terhadap kelelahan kerja dan 57,8\% dipengaruhi oleh faktor lain yang tidak diteliti.

\section{Pengujian Hipotesis.}

Pengujian hipotesis dengan menggunakan analisis PLS didasarkan pada hasil metode/ prosedur Boostrapping.

\section{a. Uji hipotesis $\mathbf{H 1}$}

Pada tabel 2 terlihat nilai $\mathrm{t}$ - statistik untuk kontruks getaran terhadap kelelahan kerja adalah 2,029. Nilai ini lebih besar dari t - tabel 2,026 (untuk $\alpha=5 \%$ dan $\mathrm{df}=37$ ) dan dengan nilai original sampel yang positif, dapat dikatakan hipotesis H1 diterima secara signifikan yaitu getaran berpengaruh terhadap kelelahan kerja.

\section{b. Uji Hipotesis $\mathbf{H} 2$}

Pada tabel 2 terlihat nilai $\mathrm{t}$ - statistik untuk kontruks kebisingan terhadap kelelahan kerja adalah 2,091. Nilai ini lebih besar dari t - tabel 2,026 (untuk $\alpha=5 \%$ 
dan $\mathrm{df}=37$ ) dan berdasarkan nilai original sampel yang positif, dapat dikatakan hipotesis $\mathrm{H} 2$ diterima secara signifikan yaitu kebisingan berpengaruh terhadap kelelahan kerja.

\section{PEMBAHASAN}

Berdasarkan hasil pengukuran faktor-faktor lingkungan kerja pada kapal pole and line yang menjadi sampel penelitian yaitu getaran dan kebisingan diketahui nilai kebisingan pada kamar mesin dan kamar awak kapal melebihi nilai ambang batas dengan besaran 90,5 dB dan $86 \mathrm{~dB}$, sedangkan pada geladak kerja $57 \mathrm{~dB}$ masih memenuhi nilai ambang batas. Pemerintah melalui Peraturan Menteri Tenaga Kerja Nomor. PER.13/MEN/X/2011 mengatur tentang Nilai Ambang Batas Faktor Fisika dan Kimia di Tempat Kerja untuk kebisingan adalah $85 \mathrm{~dB}$ dan $0,5 \mathrm{~m} / \mathrm{det}^{2}$ untuk getaran seluruh tubuh. Tingkat getaran berada dikisaran $0,8 \mathrm{~m} / \mathrm{det}^{2}-3,5$ $\mathrm{m} / \mathrm{det}^{2}$, nilai ini melebihi nilai ambang batas yang diharuskan.

Kelelahan kerja dipengaruhi oleh faktor-faktor pada lingkungan kerja. Setyawati (1997) menyatakan bahwa kelelahan yang disebabkan oleh faktor lingkungan fisik di tempat kerja antara lain oleh getaran dan kebisingan.

Berdasarkan hasil uji hipotesis $\mathrm{H} 1$ diketahui getaran berpengaruh terhadap kelelahan kerja secara signifikan dan hasil uji hipotesis $\mathrm{H} 2$ menyatakan secara signifikan kebisingan berpengaruh terhadap kelelahan kerja. Getaran dan kebisingan secara bersama berpengaruh sebesar 42,2 \% terhadap kelelahan kerja dan 57,8 \% dipengaruhi oleh faktor lain yang tidak diteliti. Hal ini sesuai dengan hasil penelitian dari Ramdan (2007) yang menyatakan lingkungan kerja yang dipengaruhi faktor getaran dan kebisingan yang tinggi berpengaruh pada timbulnya kelelahan kerja secara signifikan.

Salah satu aspek yang harus menjadi perhatian pihak perusahaan adalah kenyamanan bagi tenaga kerja saat melaksanakan pekerjaannya. Kenyamanan yang dimaksud disini adalah kenyamanan suhu, suara dan getaran. Pekerja akan dapat bekerja secara efisien dan produktif apabila lingkungan tempat kerjanya nyaman. Sebaliknya lingkungan kerja yang tidak nyaman akan mempercepat kelelahan kerja sehingga dapat mempengaruhi produktifitasnya.

Untuk mengurangi kelelahan kerja, maka lingkungan kerja harus dibuat nyaman bagi awak kapal melalui perbaikan lingkungan kerja secara teknis, seperti mengganti mesin yang memiliki tingkat getaran dan kebisingan yang tinggi melebihi nilai ambang batas dengan mesin yang memiliki tingkat getaran dan kebisingan yang memenuhi syarat kesehatan lingkungan kerja. Bila penggantian mesin tidak dapat dilakukan maka pengendalian teknis lain yang dapat dilakukan adalah dengan menambahkan peredam getaran pada mesin kapal agar mengurangi tingkat getaran dan kebisingan. Bila pengendalian secara teknis tidak dapat dilakukan maka dapat dilakukan pengendalian secara administratif seperti pengaturan giliran kerja dan penyediaan alat pelidung diri bagi awak kapal seperti pelindung telinga yang harus digunakan saat bekerja bila kebisingan di tempat kerja melebihi $85 \mathrm{~dB}$.

\section{KESIMPULAN}

1. Tingkat getaran pada kapal pole and line yang menjadi sampel penelitian berada dikisaran 0,6 $\mathrm{m} / \mathrm{det}^{2}-1,1 \mathrm{~m} / \mathrm{det}^{2}$, nilai ini melebihi nilai ambang batas yaitu $0,5 \mathrm{~m} / \mathrm{det}^{2}$. Sedangkan kebisingan di kamar mesin 89 dB, kamar abk 87 $\mathrm{dB}$ dan di geladak kerja $57 \mathrm{~dB}$. Untuk kamar mesin dan kamar abk kebisingan masih melebihi dari nilai ambang batas yang diharuskan yaitu 85 dB. Nilai ambang batas diatur oleh Peraturan Menteri Tenaga Kerja Nomor. PER.13/MEN/X/2011 tentang Nilai Ambang Batas Faktor Fisika dan Kimia di Tempat Kerja.

2. Lingkungan kerja berpengaruh terhadap stres kerja secara signifikan. Lingkungan kerja berpengaruh sebesar 35,3\% terhadap stres kerja dan $64,7 \%$ dipengaruhi oleh faktor lain yang tidak diteliti.

3. Secara signifikan lingkungan kerja berpengaruh terhadap kelelahan kerja. Lingkungan kerja berpengaruh sebesar 47,1 \% terhadap kelelahan kerja dan 52,9\% dipengaruhi oleh faktor lain yang tidak diteliti.

\section{SARAN}

1. Pengusaha dalam hal ini pengelola kapal ikan pole and line wajib memperbaiki lingkungan kerja bila diketahui paparan dari faktor-faktor pada lingkungan kerja sudah melebihi ambang batas dan juga menyediakan alat-alat pelindung diri yang diwajibkan sesuai dengan resiko bahaya pada lingkungan kerja. Agar awak kapal merasa nyaman dalam bekerja sehingga mengurangi tingkat stres kerja dan kelelahan kerja sehingga meningkatkan kinerja.

2. Awak kapal wajib menggunakannya alat pelindung diri pada tempat kerja yang nilai ambang batas faktor-faktor lingkungan kerja seperti kebisingan melebihi dari aturan yang ditetapkan.

\section{DAFTAR PUSTAKA}

Ariani Diah Novita. 2009. Skripsi: “Tinjauan FaktorFaktor Yang Mempengaruhi Tingkat Kelelahan". Depok; Fakultas Kesehatan Masyarakat; UI 
Carter, T., \& Schreiner, A. (2014). 19.2 Vibration on Board Ships. Textbook of Maritime Medicine. Tersedia: www.textbook.ncmm.no

Effendi, M. (2015). Partial Least Square (PLS). Tersedia: masud.lecture.ub.ac.id

ILO. (2013). "Seafarers bill of right", Guidance on health and Safety. Tersedia: www.itfglobal.org

ILO. (2014). Safety and Health in The use of Chemicals in The Workplaces. International Labour Organization. Tersedia: http://www.ilo.org

Lang, M. (2011). An Investigation of Organizational Culture and Job Satisfaction on board Industrial and Cruise Ships. Trondheim: Thesis, Department of Psychology, The Norwegian University of Science and Technology (NTNU). Tersedia https://brage.bibsys.no

Lubis H. S. .2009. Skripsi: "Perbedaan Kelelahan Kerja Pada Operator Antara Shift Pagi Dan
Shift Malam Di SPBU 14203163 Tanjung Morawa". Medan; Fakultas Kesehatan Masyarakat; USU

OSHAnswer. (2012). "Mental Health - Psychosocial Risk Factors in the Workplace". Tersedia: https: //www.ccohs.ca

Ramdan, I. W. (2017). Dampak Giliran Kerja, Suhu dan Kebisingan terhadap Perasaan Kelelahan Kerja di PT LJP Provinsi Kalimantan Timur. Tersedia: www. researchgate net/publication /265274799

Setyawati, Lientje. (1997). "Kelelahan dan Permasalahannya". Tersedia: http:/www. Cermin Dunia Kedokteran.com/2004/ intisari/bising.htm

Suma'mur, P., 2009. Higiene Perusahaan dan Kesehatan Kerja (Hiperkes). Jakarta: CV Sagung Seto 